\title{
RELAÇÕES FORMAIS ENTRE EXPRESSÕES CRISTALIZADAS E AS CONSTRUÇÕES VERBAIS LOCATIVAS LIVRES
}

\section{FORMAL RELATIONS BETWEEN FIXED EXPRESSIONS AND LOCATIVE DISTRIBUTIONALLY FREE VERBAL CONSTRUCTIONS}

\author{
Roana Rodrigues ${ }^{1}$ \\ Universidade Federal de Sergipe \\ Oto Araújo Vale ${ }^{2}$ \\ Universidade Federal de São Carlos \\ Jorge Baptista ${ }^{3}$ \\ Universidade do Algarve / INESC-ID Lisboa
}

\section{RESUMO}

As expressões cristalizadas (EC), sobretudo na perspectiva teórico-metodológica do Léxico-Gramática (GROSS, 1982), têm sido habitualmente tratadas na ótica de sua identificação e/ou classificação formal. As possíveis relações dessas expressões com as construções livres (CL) das quais podem (ou não) derivar não têm sido objeto de estudo sistemático neste quadro, pelo menos para o português. Neste sentido, este trabalho contribui para os estudos da lexicologia ao estabelecer relações formais entre as expressões cristalizadas do português do Brasil (VALE, 2001), construídas com verbos locativos, e as construções livres (BAPTISTA, 2013) desses mesmos verbos. Concluímos que um elevado número de ECs é construído com verbos locativos (827/3.551), sobretudo em construções nas quais o verbo seleciona um nome na posição de complemento direto e outro, na posição de complemento preposicionado locativo de destino (pregar chiclete na cruz $^{\mathrm{EC}}$ vs. pregar um quadro na parede ${ }^{C L}$ ). Além disso, as ECs podem apresentar uma estrutura idêntica à das CLs, revelando ambiguidade (suar a camisa ${ }^{\mathrm{EC} / \mathrm{CL}}$, subir o morro ${ }^{\mathrm{EC} / \mathrm{CL}}$ ); ou ainda apresentar especificidades na formação da expressão, como a seleção de um maior ou menor número de argumentos do que os que a construção verbal de base apresenta (chutar o balde $\varnothing^{\mathrm{EC}} v s$. chutar a bola no go ${ }^{\mathrm{CL}}$ ). A partir dos dados analisados, afirmamos que, apesar de a interpretação das expressões muitas vezes não ser (pelo menos inteiramente) composicional, as construções tendem a conservar a seleção dos argumentos de maneira semelhante às construções livres do mesmo verbo, bem como parte manter parte importante do significado e construção de base do verbo que entra na sua formação.

PALAVRAS-CHAVE: verbos locativos; expressões cristalizadas; léxico-gramática; português do Brasil.

\begin{abstract}
Fixed expressions (expressões cristalizadas - EC) are generally seen through the lenses of formal classification/identification, especially within the Lexicon-Grammar framework (GROSS, 1975). Within this theoretical-methodological approach, the possible relations between fixed expressions and the free verbal constructions (construções livres - CL), from which they may (or may not) derive, have not been addressed in a systematic way, at least for Portuguese. This work contributes, thus, for lexicological studies by establishing the formal relations between fixed expressions construed with locative verbs in Brazilian Portuguese (VALE, 2001), and the

\footnotetext{
1 Universidade Federal de Sergipe - Departamento de Letras Estrangeiras. r.roanarodrigues@gmail.com. ORCID: 0000-0002-7748-8716.

2 Universidade Federal de São Carlos - Departamento de Letras. otovale@ufscar.br. ORCID: 0000-0002-0091-8079.

3 Universidade do Algarve (Faro/Portugal) e Instituto de Engenharia de Sistemas e Computadores (INESC) (Lisboa/Portugal). jbaptis@ualg.pt. ORCID: 0000-0003-4603-4364.
} 
distributionally free verbal constructions (BAPTISTA, 2013) that use the same verbs. We conclude that a high number of ECs involve locative verbs $(827 / 3.551)$, mainly in constructions in which the verb presents a noun in the direct complement position and another one in a prepositional, destination-locative complement (pregar chiclete na $\mathrm{cruq}^{\mathrm{EC}} v$ s. pregar um quadro na parede $\left.^{C L}\right)$. Besides that, the ECs may present exactly the same structure as the CLs, producing ambiguous strings (suar a camisa ${ }^{\mathrm{EC} / \mathrm{CL}}$, subir o morro $^{\mathrm{EC} / \mathrm{CL}}$ ); or even display some specific characteristics in their structure, like changes in the number of complements, which may differ from that of the distributionally free verbal construction whence they are derived (chutar o balde $\varnothing^{\mathrm{EC}}$ vs. chutar a bola no gol ${ }^{\mathrm{CL}}$ ). From the data analyzed, we posit that, despite the meaning of the frozen expressions not being compositional (they are idiomatic), it partially keeps the meaning and the construction of the distributionally free verbal construction entering in its formation.

KEYWORDS: locative verbs; fixed expressions; Lexicon-Grammar; Brazilian Portuguese.

\section{INTRODUÇÃO}

Um grande número de construções verbais em língua portuguesa exprime o conceito de localização. De um ponto de vista sintático, trata-se de verbos que exigem um ou mais complementos de lugar (ou locativo) e que, no caso dos complementos preposicionais, respondem adequadamente à pergunta (Prep) onde? Tais construções locativas podem apresentar diferentes construções sintáticas, como se verifica nos exemplos de (1) a (3):

(1) O Pedro mora em São Paulo.

(2) O Pedro colocou o livro na mesa.

(3) Os alunos invadiram a sala.

Em (1), o verbo morar seleciona um complemento locativo estativo (São Paulo), neste caso introduzido pela preposição em. Nos demais exemplos, observa-se uma relação locativa dinâmica, já que os verbos denotam movimento. Em (2), o verbo colocar seleciona um nome humano com papel semântico de agente na posição de sujeito (Pedro) e um nome com o papel de objeto (o livro) na posição de complemento direto, que, por sua vez, ocupa um lugar de destino (na mesa). A frase (3) ilustra uma construção locativa transitiva direta, na qual o verbo invadir seleciona um complemento direto (a sala), interpretado como locativo de destino.

O fenômeno das construções locativas já foi descrito ou mencionado em trabalhos anteriores, seja sobre os complementos locativos, como se verifica no trabalho de Neves (2000), seja sobre a sistematização dessas construções a partir de propostas de tipologias, como em Guillet e Leclère (1992), sobre o francês; Macedo (1987) e Baptista (2013), sobre o português europeu; Corrêa e Cançado (2006) e Cançado et al (2013) sobre o português do Brasil; e Rodrigues (2016), que analisa as propostas de classificação das construções verbais locativas do português europeu e do português brasileiro, contrastando as tipologias apresentadas por Baptista (2013) e Cançado et al (2013).

As expressões cristalizadas (ou expressões fixas) ${ }^{4}$ verbais podem ser definidas como as construções nas quais o verbo e pelo menos outro constituinte da frase são distribucionalmente fixos. O significado da expressão cristalizada muitas vezes não resulta da composição do significado individual que esses elementos apresentam quando ocorrem em outras construções (VALE, 2001; BAPTISTA et al., 2005), sendo, por isso, considerada idiomática. A frase (4) ilustra uma expressão cristalizada da língua portuguesa na qual o verbo (meter) seleciona os

\footnotetext{
${ }^{4}$ Segundo Vale (2001, p. 1), o termo expressão fixa parece levar a uma concepção de um estado de fixidez ou rigidez que não está necessariamente presente na maioria das expressões. Por isso, muitos autores optam pelo termo expressão cristalizada, como utilizaremos neste artigo.
} 
complementos fixos (o rabo e entre as pernas) e toda a construção apresenta uma interpretação não composicional: 'ir embora vencido e bumilhado':

Os líderes do protesto meteram o rabo entre as pernas ${ }^{5}$.

(PB-C1P2)

Muitas expressões cristalizadas são construídas com verbos locativos, como se observa nas frases (5a) e (6a), e apresentam estruturas sintáticas semelhantes às das construções livres desses mesmos verbos, exemplificadas nas frases (5b) e (6b).

(5) a. O Pedro atravessou um campo minado.

(5) b. O Pedro atravesson a rua.

(6) a. O Pedro jogou a sorte pela janela.

(6) b. O Pedro jogou o vaso no chão.

Em (5a), a expressão cristalizada, classificada por Vale (2001) como PB-C1, é construída com o verbo atravessar, e apresenta um complemento direto fixo (um campo minado), que, numa interpretação literal, corresponderia a um complemento com valor locativo genérico. A expressão apresenta uma estrutura homóloga à da construção livre do verbo atravessar, ilustrada em (5b), que, segundo Baptista (2013), é integrada na classe 38L1, de construções transitivas diretas de predicados locativos dinâmicos. A construção livre com o verbo atravessar permite qualquer nome que admita a interpretação de lugar na posição de complemento locativo. A expressão cristalizada, por sua parte, admite apenas o complemento um campo minado, tendo um significado não composicional que se poderia definir como 'passar por uma situação perigosa'.

A frase (6a) é construída com o verbo jogar e apresenta uma estrutura semelhante à construção livre com o mesmo verbo, que é classificado por Baptista (2013) na classe 38LD. Os verbos dessa classe correspondem a predicados locativos dinâmicos e apresentam uma construção com um sujeito agente, um complemento direto com o papel de objeto e um complemento preposicionado com o valor de locativo de destino. $\mathrm{Na}$ expressão cristalizada, o complemento direto é ocupado pelo nome abstrato sorte e o complemento preposicional locativo pela janela designa um lugar de trajetória. Os elementos que compõem a expressão cristalizada, apesar de apresentarem estrutura sintática semelhante à construção livre, não admitem variações de forma e seu significado global tem, obviamente, um valor idiomático, não composicional, próximo de 'desperdiçar uma oportunidade'.

As expressões cristalizadas têm sido habitualmente tratadas na ótica de sua identificação e/ou classificação formal, sobretudo na perspectiva teórico-metodológica do Léxico-Gramática (VALE, 2001; BAPTISTA et al., 2005). As possíveis relações dessas expressões com as construções livres das quais podem (ou não) derivar não têm sido ainda objeto de estudo sistemático neste quadro, pelo menos para a língua portuguesa, salvo na medida em que permitem determinar com precisão e numa base formal as propriedades que definem as expressões cristalizadas. Neste sentido, estabelecemos, neste estudo, as relações formais entre as expressões cristalizadas construídas com verbos locativos com as construções livres desses mesmos verbos, a fim de determinar mais precisamente as relações que se possam estabelecer entre os dois tipos de construções e, assim, delinear eventuais padrões no processo de formação dessas expressões cristalizadas.

$O$ presente artigo se organiza da seguinte maneira: inicialmente descreveremos a classificação das construções verbais locativas livres da base de dados verbais ViPEr,

\footnotetext{
5 Os exemplos das expressões cristalizadas e os das construções verbais livres apresentados deste artigo foram retirados e/ou adaptados de Vale (2001) e de Baptista (2013). Os códigos entre parêntesis referem-se à classe em que tal expressão cristalizada é classificada, segundo os critérios apresentados por estes autores. Tais critérios de classificação serão apresentados nas seções seguintes deste artigo.
} 
desenvolvida por Baptista (2013). Ressalta-se que, das mais de 7.000 construções verbais livres descritas nessa base de dados, 1.142 são classificadas como locativas, daí nosso interesse em descrever especificamente tais construções, por ser de número expressivo em língua portuguesa. Em seguida, apresentaremos as classes de expressões cristalizadas do português do Brasil propostas por Vale (2001). Finalmente, discutiremos a distribuição das construções das expressões cristalizadas pelos tipos de construções locativas livres, o seu comportamento e principais características.

\section{Construções verbais locativas livres}

O ViPEr (BAPTISTA, 2013) ${ }^{6}$, é uma base de dados dos verbos do português europeu, que tem como arcabouço teórico-metodológico o Léxico-Gramática (GROSS, 1975, 1981). Esse trabalho destaca-se pela quantidade de dados analisados, já que apresenta a descrição de 130 propriedades sintáticas (estruturais, distribucionais e transformacionais) e propriedades semânticas de mais de 7.000 construções verbais, organizadas em 71 classes. Neste quadro teórico-metodológico, a unidade mínima de análise é a frase elementar, ou seja, a frase que é constituída apenas pelo elemento predicador, neste caso, um verbo, e pelos elementos tidos como essenciais para a expressão do predicado (sujeito e complementos essenciais). As descrições linguísticas do ViPEr estão formalizadas em matrizes léxico-sintáticas (tábuas), nas quais as linhas apresentam as entradas lexicais e as colunas, suas propriedades, tais como o número e o tipo de argumentos, as preposições que introduzem esses argumentos, o preenchimento lexical das posições argumentais, as possíveis transformações como a apassivação, os papeis semânticos dos diferentes argumentos, entre outros.

Apesar de se tratar de uma base de dados do português europeu, Rodrigues (2016) contrastou as construções verbais locativas do ViPEr (BAPTISTA, 2013) com o Catálogo de verbos de mudança do português brasileiro (CANÇADO et al, 2013) e constatou que, de maneira geral, as propriedades sintático-semânticas dos verbos locativos descritas no ViPEr são praticamente idênticas às dos verbos correspondentes na variante do português brasileiro. Por este motivo, neste trabalho, utilizamos o ViPEr como nossa base de dados de referência.

De todas as construções verbais analisadas, 1.142 estão classificadas como construções locativas, que se organizam em 12 classes léxico-sintáticas. A Tabela 1 apresenta o código convencional que identifica cada classe, a respectiva estrutura, um exemplo ilustrativo e o número de verbos de cada uma das classes de construções locativas do ViPEr.

\begin{tabular}{|c|c|c|c|c|}
\hline Classe & Estrutura & Exemplo & & \# \\
\hline $35 \mathrm{LD}$ & $N_{0} V$-din Loc $N_{1} \operatorname{loc}_{1}$ & entrar & O Pedro entrou na sala. & 193 \\
\hline 35LS & $\mathrm{N}_{0} V$-stat Loc $\mathrm{Nloc}_{1}$ & viver & O Pedro vive em Lisboa. & 32 \\
\hline 37LD & $\mathrm{N}_{0}$ Vdin Loc-s1 Nloc Loc-d $_{2}$ Nloc $_{2}$ & viajar & O Pedro viajou daqui para ali. & 117 \\
\hline $38 \mathrm{L1}$ & $N_{0} V N \operatorname{Noc}_{1}$ & invadir & O Pedro invadiu a sala. & 205 \\
\hline $38 \mathrm{~L} 2$ & $N_{o}$ Nloc-v Nobj $j_{1}[\mathrm{~V}=$ pôr em Nloc $]$ & enjaular & O Pedro enjaulou o leão. & 39 \\
\hline $38 \mathrm{L3}$ & Nloco $V$ Nobj $_{1}$ & encerrar & A jaula encerrava a fera. & 12 \\
\hline $38 \mathrm{~L} 4$ & $N_{0}$ Nobj-v Nloc-d ${ }_{1}[V=$ pôr Nobj] & apimentar & O Pedro apimentou a comida. & 122 \\
\hline 38L5 & $N_{0}$ Nobj-v Nloc-si $[V=$ tirar Nobj] & desengordurar & O Pedro desengordurou o prato. & 11 \\
\hline $38 \mathrm{LD}$ & $\mathrm{N}_{0} V \operatorname{din} \mathrm{N}_{1} \mathrm{Loc}_{-d_{2}} \mathrm{Nloc}_{2}$ & pousar & O Pedro pouson o livro na mesa. & 281 \\
\hline 38LS & $N_{0} V \operatorname{din} N_{1} \operatorname{Loc}_{-s_{2}}$ Nloc $_{2}$ & retirar & O Pedro retirou o livro da mesa. & 77 \\
\hline 38LT & $\mathrm{N}_{0} V \operatorname{din} \mathrm{N}_{1} \mathrm{Loc}_{-} \mathrm{s}_{2} \mathrm{Nloc}_{2} \mathrm{Loc}_{-d_{3}} \mathrm{Nloc}_{3}$ & transferir & O Pedro transferiu o livro daqui para ali. & 50 \\
\hline $38 R$ & $N_{0} V$ stat $N_{1} \operatorname{Loc}_{2} N_{2}$ & situar & O Pedro situou o Butão no mapa. & 3 \\
\hline
\end{tabular}

${ }^{6}$ Para este estudo usamos a versão beta 1.58, de 10 de outubro 2016. 
Tabela 1. Classes dos verbos locativos livres do português europeu

Fonte: Baptista, 2013

Como se vê na Tabela 1, um fator determinante para a classificação dos verbos é a transitividade do verbo (i.e. o fato de o verbo se construir com complemento direto) e o número de complementos essenciais da frase de base. No caso das classes locativas, verificou-se também o caráter estativo ou dinâmico do predicado, ou seja, se o processo descrito pelo verbo implica (ou não) movimento (do objeto). As classes 38R (detectar, localizar e situar), 38L3 (abrigar, acomodar, albergar, etc.) e 35LS (acampar, morar, residir, viver, etc.) exprimem um predicado de localização estativo. As demais classes agrupam construções locativas dinâmicas e consideram, então, se o complemento locativo exprime um lugar de origem, trajetória ou destino. A classe 35LD, por exemplo, é constituída por verbos que exprimem um predicado de movimento (dinâmico) e apresentam um complemento preposicionado com valor de lugar de destino. Nessa classe estão os verbos como entrar, refugiar-se, etc.

\section{O Pedro entrou na sala.}

Além das construções preposicionadas, Baptista (2013) descreve também as construções locativas transitivas diretas. Na classe 38L1 estão os verbos que estabelecem uma relação entre o sujeito, interpretado como objeto de lugar, e o complemento direto, entendido como o lugar. Esta relação locativa pode ser expressa por uma construção preposicional <objeto> estar em <lugar>. Como ilustra o exemplo (8a), com abandonar, fazem parte dessa classe verbos como: atravessar, saltar, subir, etc. Para a identificação dos diferentes tipos de complementos locativos, realiza-se, neste caso, o teste com a paráfrase: antes, durante ou depois da ação, <objeto> está em <lugar>, como se pode ver na frase (8b):

(8) a. O Pedro abandonou a sala.

(8) b. Antes de abandonar a sala, o Pedro está na sala.

No ViPEr é apresentada também a descrição de construções locativas transitivas diretas que envolvem a noção de Fusão. Esta operação foi proposta originalmente por Gross (1981) para dar conta de relações parafrásticas (transformacionais) entre frases, nas quais um complemento, tipicamente um complemento adjunto adverbial, e um verbo se fundem, dando origem, superficialmente, a uma frase simples. Trata-se, no caso das construções locativas, das classes 38L2, 38L4 e 38L5, que podem ser analisadas pela Fusão dos operadores pôr ou tirar e um predicado locativo, que designam, respectivamente, destino e origem:

(9) a. O Pedro engaiolou o pássaro.

(9) b. O Pedro pôs \# o pássaro está numa gaiola.

(9) c. $=$ O Pedro pôs \# o pássaro numa gaiola.

(10) a. O Pedro lubrificou o motor.

(10) b. O Pedro pôs \# o lubrificante está no motor.

(10) c. $=$ O Pedro pôs \# o lubrificante no motor.

(11) a. O Pedro desengorduron o fogão.

(11) b. O Pedro tirou \# a gordura está no fogão.

(11) $\quad$ c. = O Pedro tirou \# a gordura do fogão.

A classificação sistemática de Baptista (2013) apresenta as diversas propriedades e particularidades das construções verbais locativas livres em língua portuguesa, contribuindo para 
uma descrição linguística minuciosa, assim como para a área de Processamento de Língua Natural (PLN), já que se constitui como um recurso linguístico com informações (sintático-semânticas) de elevada granularidade.

Na próxima seção, apresentaremos a proposta de tipologia das expressões cristalizadas do português brasileiro, de acordo com Vale (2001).

\section{Expressões cristalizadas verbais}

Segundo Vale (2001), as expressões cristalizadas (ou fixas) são aquelas em que o verbo e pelo menos outro constituinte da frase são distribucionalmente fixos. As expressões cristalizadas verbais, que são o nosso objeto de estudo, se constituem em torno de um verbo, cuja morfologia em nada se difere da morfologia dos verbos livres, ou seja, são conjugados concordando sempre com o sujeito da frase, conforme apresenta Vale (2001, p.37) nos exemplos (12a) e (12b):

a. Odilon Guedes chove no molhado.

(12) b. Sei que chovo no molhado.

Sendo assim, Vale (2001, p. 45) afirma que essas expressões podem ser construídas com um sujeito fixo ou com um sujeito livre. As expressões com sujeito fixo podem ser: (i) sem complemento (A cobra vai fumar); (ii) com complemento fixo (A montanha pariu um rato); (iii) com complemento fixo e um complemento determinativo livre (O sucesso subiu à cabeça de Fulano) e (iv) com complemento direto fixo e complemento preposicional livre (Entrou areia na negociação). No caso das expressões com sujeito livre, encontramos as construções: (i) com um complemento fixo (Fulano caiu do cavalo); (ii) com dois complementos fixos (Fulano mudou da água para o vinho); (iii) com complemento fixo e complemento determinativo livre (Fulano lavou a alma da oposição); e (iv) com dois complementos fixos e um complemento determinativo livre (Fulano jogou mel na boca dos investidores). As expressões com sujeito fixo tendem a apresentar uma fronteira muito tênue com os provérbios. Dessa maneira, a classificação proposta por Vale (2001) centra-se apenas nas expressões com sujeito livre.

Para a classificação das expressões cristalizadas verbais do português do Brasil, Vale (2001) teve como arcabouço teórico-metodológico o Léxico-Gramática, que propõe uma análise sistemática visando a exaustividade do fenômeno que se está estudando. O léxico das ECs foi assim organizado em classes, construindo-se tábuas com as propriedades de cada item lexical. $\mathrm{Na}$ Tabela 2 temos as 10 classes distintas das 3.551 expressões cristalizadas classificadas por Vale (2001).

\begin{tabular}{|c|c|c|c|}
\hline Classe & Estrutura & Exemplo & \# \\
\hline PB-C1 & $N_{0} V C_{1}$ & O Pedro suou a camisa para subir de cargo. & 1.206 \\
\hline PB-CP1 & $N_{0} V \operatorname{Prep} C_{1}$ & O Pedro nada contra a maré. & 660 \\
\hline PB-CDH & $N_{0} V(C \text { de Nhum })_{1}$ & O Pedro encheu o meu saco hoje. & 157 \\
\hline PB-CDN & $N_{0} V(C \text { de } N)_{1}$ & A dinbeirama azeita a engrenagem das campanbas. & 101 \\
\hline PB-C1PN & $N_{0} V C_{1} \operatorname{Prep} N_{2}$ & Nenbum político meteu o bedelho nos programas de tv. & 321 \\
\hline PB-CNP2 & $N_{0} V N_{1} \operatorname{Prep} C_{2}$ & O cantor levou o público à loucura. & 341 \\
\hline PB-CP1PN & $N_{0} V \operatorname{Prep} C_{1} \operatorname{Prep} N_{2}$ & O Pedro acabou com a raça do João. & 127 \\
\hline PB-C1P2 & $N_{0} V C_{1} \operatorname{Prep} C_{2}$ & Os empresários botaram as cartas na mesa. & 423 \\
\hline PB-CPP & $N_{o} V \operatorname{Prep} C_{1} \operatorname{Prep} C_{2}$ & O Pedro mudou da água para o vinho. & 90 \\
\hline PB-C1P2DN & $N_{0} V C_{1} \operatorname{Prep}(C \text { de } N)_{2}$ & O Pedro coloca a mão no fogo pela Maria. & 125 \\
\hline \multicolumn{3}{|l|}{ TOTAL } & 3.551 \\
\hline
\end{tabular}

Tabela 2 - Classes das expressões cristalizadas do português brasileiro

Fonte: Vale, 2001 
Para cada expressão, foram analisadas propriedades sintáticas, como a apassivação; propriedades distribucionais, como o caráter humano/não-humano do nome que ocupa a posição de sujeito ou de complemento distribucionalmente livre; além das propriedades semânticas valenciais (ação, processo, ação-processo e estado).

As classes PB-C1 e PB-CP1 (as classes mais produtivas) apresentam uma relativa homogeneidade. Ambas apresentam um sujeito livre e um complemento fixo. A principal diferença é que em PB-C1, como se verifica no exemplo (13), o constituinte fixo é um complemento direto; já em PB-CP1, o complemento fixo é introduzido por preposição, (14).

(13) Os corruptos sentam praça em todos os partidos do mundo.

(14) Pefelistas dizem que FHC brinca com fogo.

As classes PB-CDH, PB-CDN, PB-C1PN, PB-CNP2 e PB-CP1PN têm em comum o fato de possuírem um sujeito livre e apenas um elemento cristalizado. A classe PB-CPN2, por exemplo, agrupa as expressões cujo complemento direto é livre e o complemento preposicionado é fixo, como se vê em (15):

Depoimentos põem a lenda por terra.

(CNP2)

Por sua vez, as classes PB-C1P2, PB-CPP e PB-C1P2DN se caracterizam por possuírem dois complementos fixos. Na classe PB-C1P2, pode-se diferenciar claramente os complementos cristalizados. Segundo Vale (2001, p. 167), "é interessante notar que o segundo elemento cristalizado é, na grande maioria dos casos, uma espécie de locativo", que pode ser tanto de origem (16a), quanto de destino (16b) ou ainda estativo (16c):

(16) a. A inventividade com que Rodriguez tira leite de pedra ao narrar a saga.

(16) b. É hora de pôr as cartas na mesa.

(16) c. Em vez de procurar agulha em palheiro, abra o "Netscape".

A principal diferença entre as classes PB-C1P2DN e PB-C1P2 está no fato de que, na classe PB-C1P2DN, o segundo complemento tem um complemento interno (determinativo) distribucionalmente livre, como se verifica em (17); diferente da classe PB-C1P2, (18), em que cada complemento é fixo e não tem, por sua vez, outros complementos determinativos. A grande maioria das expressões desta classe é construída em torno de verbos como colocar, pôr e correlatos.

(17) Mas, [...] o partido põe as mãos na massa da realidade infectada.

(18) Só que em vez de serem solidários, compreenderem e ajudarem aqueles

(PB-C1P2DN)

que põem a mão na massa, ficam teorizando.

(PB-C1P2)

Partindo da classificação das construções verbais locativas livres do ViPEr (BAPTISTA, 2013) e das expressões cristalizadas do português do Brasil (VALE, 2001), apresentaremos, na próxima seção, a análise das expressões cristalizadas construídas com verbos locativos em língua portuguesa, salientando os seus pontos comuns e divergentes.

\section{Os verbos locativos nas expressões cristalizadas}

Para obter os dados aqui descritos, alinhamos cada expressão cristalizada estudada por Vale (2001) com as construções verbais livres do ViPEr (BAPTISTA, 2013). Em seguida, selecionamos apenas as expressões cristalizadas construídas com os verbos classificados em classes locativas do ViPEr e verificamos o comportamento do verbo na seleção dos argumentos (sujeito e complementos) que compunham a frase de base. 
A partir do alinhamento das expressões cristalizadas com as construções verbais livres, foi possível observar que há expressões nas quais permanece a interpretação locativa do verbo de base, como sucede nas frases (19a)-(19b) e (20a)-(20b):

a. O Pedro vive numa torre de marfim.

b. O Pedro vive em São Paulo.

(20) a. O Pedro partiu da estaca zero.

(20) b. O Pedro partiu de São Paulo (para Manaus).

Em (19a), a expressão cristalizada viver numa torre de marfim é construída com o verbo viver. Essa estrutura é homóloga à da construção livre, representada em (19b), que é classificada no ViPEr na classe 35LS. A construção livre com o verbo viver admite qualquer nome com interpretação de lugar na posição de complemento preposicional locativo (estativo). A expressão cristalizada, por sua parte, admite apenas o complemento numa torre de marfim, tendo toda a expressão um caráter idiomático que corresponde a 'viver isolado do mundo, acima dos outros; considerar-se muito importante e superior aos demais'. A expressão cristalizada ilustrada em (20a) é construída com o verbo partir e apresenta uma construção semelhante à construção livre com o mesmo verbo, que é classificado no ViPEr na classe 37LD. Os verbos dessa classe correspondem a predicados locativos dinâmicos e apresentam uma construção com complementos preposicionados de natureza locativa (de origem, de trajetória ou de destino), os quais podem combinar-se entre si. Ao contrário da construção livre, a expressão cristalizada com o verbo partir, em (20a), não admite um complemento locativo de destino.

Encontramos também construções fixas não-locativas com esses mesmos verbos de base, como sucede nas frases (21) e (22):

(21) a. O Pedro vive de ares.

(PB-CP1)

(21) b. O Pedro vive da especulação da Bolsa de Valores.

(22) a. O Pedro partiu a cara do João.

(22) b. O Pedro partiu o braço (do João).

O verbo viver da expressão cristalizada ilustrada em (21a) se assemelha à construção livre desse mesmo verbo, a qual pertence à classe 08 do ViPEr, constituindo um predicado não-locativo. Trata-se de uma construção com complemento preposicional que é geralmente preenchido por uma completiva ou por um nome abstrato (ação). $\mathrm{Na}$ frase (22a), com o verbo partir, a expressão cristalizada é uma construção transitiva direta com o complemento direto obrigatoriamente preenchido por um nome parte do corpo, cujo complemento determinativo, preenchido por um nome humano, é distribucionalmente livre. O significado global da expressão é 'bater ou dar uma surra em alguém'. A construção livre classificada no ViPEr como 32CL e exemplificada em (22b) corresponde ao sentido literal do verbo: 'fraturar (um osso)'.

Estes exemplos demonstram que, no processo de cristalização, a construção de base (livre) de cada verbo se encontra subjacente às expressões fixas. Se um mesmo verbo apresenta diferentes construções sintáticas (livres), cada construção pode dar origem a diferentes tipos de construções cristalizadas, cada uma conservando, em parte, o significado da forma (livre) que lhe serviu de base.

Neste trabalho, como já foi mencionado, estudaremos apenas as expressões cristalizadas construídas por verbos pertencentes a classes de construções locativas, como os casos ilustrados nas frases (19a) e (20a). Deste modo, das 3.551 expressões cristalizadas descritas por Vale (2001), determinamos que 827 são constituídas por verbos de construções locativas, segundo a classificação do ViPEr. A Tabela 3 apresenta a distribuição das expressões cristalizadas, 
envolvendo verbos que pertencem às diferentes classes de construções verbais locativas livres do ViPEr.

\begin{tabular}{|c|c|c|c|c|c|c|c|c|c|c|c|}
\hline $\begin{array}{l}\text { EC/ } \\
\text { ViPEr }\end{array}$ & $\begin{array}{l}\vec{\theta} \\
\dot{\beta}\end{array}$ & 矛 & 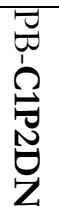 & 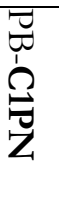 & 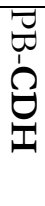 & $\begin{array}{l}\vec{\sigma} \\
\overbrace{Z}^{\prime} \\
Z\end{array}$ & 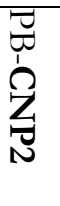 & 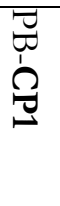 & 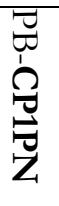 & 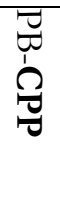 & Total \\
\hline 35LD & & 1 & & & & & & 93 & 7 & 36 & 137 \\
\hline $35 \mathrm{LS}$ & & & & & & & & 12 & & 2 & 14 \\
\hline $37 \mathrm{LD}$ & & & & & & & & 93 & 1 & 18 & 112 \\
\hline 38L1 & 29 & 3 & 2 & 1 & 8 & 3 & & 1 & & & 47 \\
\hline $38 \mathrm{~L} 2$ & & 1 & & & & & & & & & 1 \\
\hline 38L4 & 10 & 1 & & & 3 & 4 & & & & & 18 \\
\hline 38LD & 20 & 125 & 88 & 75 & 2 & & 97 & 15 & 2 & 1 & 425 \\
\hline $38 \mathrm{LS}$ & 1 & 28 & 6 & 11 & & 1 & 15 & & & & 62 \\
\hline $38 \mathrm{LT}$ & 4 & & & 3 & & & 1 & & & 3 & 11 \\
\hline Total & 64 & 159 & 96 & 90 & 13 & 8 & 113 & 214 & 10 & 60 & 827 \\
\hline
\end{tabular}

Tabela 3. Distribuição das expressões cristalizadas pelos tipos de construções verbais locativas Fonte: própria autoria

Os verbos das classes 38L3, 38L5 e 38R do ViPEr (não representados na tabela acima) não aparecem na construção de nenhuma expressão cristalizada estudada. Essa ausência pode dever-se principalmente ao fato de se tratarem de classes que englobam um pequeno número de construções verbais $(12,11$ e 3 construções verbais descritas em cada classe, respectivamente), sendo construções bastante específicas e, portanto, menos usuais.

Quanto à distribuição das expressões cristalizadas pelos tipos de construções locativas do ViPEr, verifica-se que muitas expressões estão relacionadas às construções locativas livres das classes 38LD (425), 35LD (137), 37LD (112) e 38LS (62).

As expressões cristalizadas da classe PB-C1 (64 EC) correspondem, em sua maioria, aos verbos da classe 38L1 do ViPEr, constituindo construções transitivas diretas, como em (23):

$$
\text { O Pedro subiu (a ladeira }+ \text { a serra }+ \text { o morro). }
$$

Como se observa na frase (23), algumas expressões cristalizadas são superficialmente idênticas a construções livres, podendo, portanto, ser ambíguas. Nestes casos, a determinação do sentido da expressão só é possível considerando o contexto em que é usada. Contudo, quando empregues no seu sentido figurado, as expressões muitas vezes não admitem um modificador do nome do complemento direto, seja um adjetivo, seja um complemento adequado, como se verifica na frase (24a):

a. O jogador suou a camisa ( ${ }^{\circ}$ azul / ${ }^{\circ}$ de poliéster) no jogo ${ }^{7}$.

$$
\text { b. O jogador suou a camisa (azul }+ \text { de poliéster) no jogo. }
$$

Sendo assim, a construção livre com o verbo suar (24b) admite um modificador do nome que ocupa a posição de complemento direto (camisa azul ou de poliéster). Já a expressão cristalizada

\footnotetext{
${ }^{7} \mathrm{O}$ símbolo (०) indica que a frase é aceitável, mas o seu significado é composicional, ou seja, quando se trata de uma EC, a presença deste elemento é inaceitável.
} 
superficialmente idêntica e construída pelo mesmo verbo e nome (suar a camisa), ilustrada em (24a) não permite a entrada de um elemento modificador desse nome.

Das 18 EC constituídas com verbos da classe 38L4, 10 correspondem a verbos da classe PB-C1. As construções da classe 38L4 são construções transitivas diretas locativas, cujo verbo é formado sobre um nome não humano, interpretado como o objeto, e o complemento direto desempenha o papel semântico de locativo de destino. É o caso da frase (25), com os verbos lubrificar e azeitar. tal como no exemplo (24a)-(24b), acima, a expressão cristalizada é ambígua, podendo ser igualmente interpretada de forma literal, o que dependerá do contexto em que for usada:

$$
\text { O Pedro (lubrificou + ą̧eitou }) \text { a (engrenagem }+ \text { máquina). }
$$

(PB-C1/38L4).

Da análise dos dados, ressalta-se ainda a relevância da correspondência entre as classes PB-C1 e 38LD. Os verbos da classe 38LD selecionam um nome na posição de complemento direto com valor de objeto e um complemento preposicionado, com o papel de locativo de destino. Dos 20 casos de correspondência entre as classes PB-C1 e 38LD, 18 EC não admitem um complemento preposicionado locativo, ou seja, a EC se reduz a uma construção com um elemento fixo que, na construção livre, corresponderia a um complemento direto. Desse modo, verifica-se nestes casos algum distanciamento entre a $\mathrm{EC}$ e a CL, já que a última seleciona não só um complemento direto, como também, com caráter de complemento essencial, o complemento preposicionado interpretado como locativo de destino. As frases (26a) e (27a), com os verbos chutar e carregar, ilustram esse caso:

(26) a. O Pedro chutou o balde ( ${ }^{\circ}$ para o alto $+{ }^{\circ} \mathrm{o}$ João $+{ }^{\circ} \mathrm{O}$ gol).

(26) b. O Pedro chutou o balde (para o alto + o João + o gol).

(27) a. O Pedro carregon o piano ( ${ }^{\circ}$ para o caminhão).

(27) b. O Pedro carregou o piano (para o caminhão).

Das 159 EC da classe PB-C1P2, 125 se constroem com verbos locativos da classe 38LD. Nestas expressões, verifica-se uma combinatória cristalizada do verbo com dois nomes: um na posição de complemento direto e outro na posição de complemento preposicionado, como se vê em (28a):

a. O Pedro (colocou + meteu + pôs $)$ a mão na graxa.

b. O Pedro (colocou + meteu + pôs $)$ o livro na mesa.

Em (28a) os verbos colocar, meter e pôr combinam-se com dois elementos formando várias ECs, a saber: (i) um nome na posição de complemento direto (a mão); e (ii) um nome na posição de complemento preposicionado (na graxa). Esta construção assemelha-se ao comportamento dos complementos locativos de destino, introduzido pela preposição em, como acontece na construção livre exemplificada em (28b).

As expressões da classe PB-C1P2 estabelecem ainda relação com os verbos da classe 38LS do ViPEr. À diferença da classe 38LD, que selecionam complementos locativos de destino, os verbos da 38LS selecionam um complemento preposicionado locativo de origem, como na frase (29). Ainda que o valor semântico locativo dos complementos preposicionais na CL pareça se manter nas EC construídas com esses verbos locativos, o trabalho de Vale (2001) não a considerou como um critério classificatório dessas expressões.

(29) a. O Pedro tirou a mão da massa.

(29) b. O Pedro tiron o livro da gaveta. 
As expressões classificadas nas classes PB-C1PN e PB-CNP2 são semelhantes às da classe PB-C1P2, na medida em que se trata de construções com um complemento direto e um complemento preposicionado. Para a grande maioria dos casos em que estas EC envolvem um verbo locativo, trata-se de verbos da classe 38LD do ViPEr (75/90 e 97/113, para as classes PB-C1PN e PB-CNP2, respectivamente). Na classe PB-C1PN estão as expressões em que o primeiro complemento é fixo e o segundo é livre, como na frase (30).

A cantora jogou um balde de água fria (nos fãs $+{ }^{\circ}$ nas plantas $+{ }^{\circ}$ no jardim).(PB-C1PN/38LD)

$\mathrm{Na}$ construção livre 38LD ilustrada em (30), o verbo jogar seleciona um elemento na posição de complemento direto (no caso, um balde de água fria) e, na posição de complemento locativo preposicionado, um nome de lugar (jardim) ou, ainda, um nome humano (fãs) e um nome não-humano (plantas), este último interpretado metonimicamente como o lugar em que esses elementos estão. Por sua vez, a expressão cristalizada PB-C1PN, constituída pelo mesmo verbo (jogar), apresenta um complemento direto fixo (um balde de água fria) e um elemento que, apesar de ser distribucionalmente livre, apenas parece permitir o seu preenchimento por um nome humano (nos fãs). Como em outros casos que já apresentamos antes, algumas destas EC dão origem a expressões formalmente ambíguas, daí a notação que adotamos no exemplo (30). A interpretação idiomática, sinônima de 'decepcionar, desiludir', só se verifica quando o complemento direto de jogar é um balde de água fria; além disso, verifica-se que o conjunto de restrições distribucionais da EC sobre o complemento preposicional é maior do que as restrições que a construção livre do mesmo verbo impõe ao preenchimento lexical dessa posição argumental.

Já na classe $\mathrm{PB}-\mathrm{CNP} 2$, a posição sintática dos elementos fixos e livres é inversa à que é apresentada pelas construções da classe PB-C1PN. Agora, o complemento direto é distribucionalmente livre e o complemento preposicional é fixo com o verbo, como se vê no exemplo (31a).

(31) a. O Pedro chutou a carreira promissora para escanteio.

(PB-CNP2)

(31) b. O Pedro chutou a bola para escanteio.

Em (31a), a EC é constituída por um complemento preposicionado fixo com o verbo (chutar para escanteio) e apresenta um complemento direto distribucionalmente livre (a carreira promissora). A construção livre deste verbo apresenta idêntica estrutura sintática. Ressalte-se, no entanto, que o nome que ocupa a posição de complemento direto na construção livre tende a ser um nome concreto (bola), enquanto a expressão cristalizada apresenta, na maioria dos casos, nomes abstratos para ocupar essa posição argumental.

As classes PB-C1P2DN (96/827), PB-CDH (13/827), PB-CDN (8/827) e PB-CP1PN (10/827) apresentam semelhanças sintáticas com as construções livres das classes 38LD, 38L1, 38L4 e 35LD, respectivamente. No entanto, distanciam-se das mesmas ao selecionarem um maior número de argumentos do que os que as construções livres dos mesmos verbos apresentam:

(32) a. O Pedro colocon o dedo na ferida dos fiscais.

(PB-C1P2DN)

b. O Pedro colocou o livro na mesa (do fiscal).

(33) a. A dinheirama azeita a engrenagem das companhias.

(PB-CDN)

b. O Pedro azeita a engrenagem (do carro).

(34) a. O Pedro entrou para o clube dos desempregados.

(34) b. O Pedro entrou no clube (aquático). 
Nos exemplos (32a), (33a) e (34a), as expressões cristalizadas apresentam sempre, após um complemento direto cuja cabeça é fixa com o verbo, um complemento determinativo livre (do fiscal, das companbias, dos desempregados). Já as construções livres de (32b), (33b) e (34b), construídas com esses mesmos verbos, não selecionam obrigatoriamente esse complemento determinativo.

As expressões da classe PB-CP1 estão relacionadas principalmente com as construções livres dos verbos das classes 35LD (93/214) e 37LD (93/214) do ViPEr. Nas frases (35a) e (36a), observa-se a relação com os verbos da classe $35 \mathrm{LD}$, em que se verifica uma construção preposicionada, que exprime um predicado dinâmico e seleciona um complemento locativo de destino.

a. O Pedro entrou (na raia + na reta final + na lama + pela janela).

b. O Pedro entrou na sala (pela janela).

(36) a. O Pedro cain (na rede + no mato + das nuvens).

(36) b. O Pedro cain (no buraco do esgoto + da cama).

Em (35a), as diversas expressões cristalizadas ilustradas apresentam uma construção sintática idêntica à da construção livre, exemplificada em (35b). De um modo geral, estes verbos apresentam um complemento locativo de destino. Apenas o complemento fixo pela janela se distancia do padrão sintático da construção livre com o verbo entrar, já que pode ser interpretado como um complemento locativo de trajetória, que é um termo acessório (adjunto) da construção livre. Em (36a), a estrutura das expressões cristalizadas corresponde à das construções livres do mesmo verbo, inclusive pela possibilidade de apresentarem tanto um complemento preposicionado locativo de destino (no mato vs. no buraco), quanto um complemento de origem (das nuvens vs. da cama).

A classe 37LD do ViPEr engloba construções verbais com dois complementos preposicionados de natureza locativa. Por convenção, o primeiro complemento exprime um locativo de origem e o segundo, um locativo de destino. No entanto, um desses complementos é muitas vezes omitido no discurso, apenas aparecendo explicitamente ou o locativo de origem ou o de destino. Note-se, no entanto, que, em várias expressões cristalizadas, apenas um dos complementos locativos pode ocorrer, ora mantendo-se apenas o locativo de origem (37a) ou o de destino (38a):

a. O Pedro sain do armário.

b. O Pedro sain da sala (para o quarto).

(38) a. O Pedro foi (para o outro mundo + para um bom lugar).

b. O Pedro foi (da Bahia) para o Rio de Janeiro.

Há, porém, certos casos de EC que parecem conservar ainda, pelo menos parcialmente, a facultatividade de um dos complementos locativos, que se observa nas construções livres correspondentes do mesmo verbo. Assim, compare-se (38a) com (38c) e (38d):

(38) c. ?O Pedro foi deste [mundo] para o outro mundo.

(PB-CP1)

d. *O Pedro foi deste [lugar] para um bom lugar.

(PB-CP1)

Encontramos atestações da forma de (38c), como, por exemplo:

E lá restei eu sozinha, quando meu marido também se foi deste para o outro mundo.

Durante horas, ficava olhando a vida lá fora, pela janela do rancho.

8 Extraído de: <http://www.construirnoticias.com.br/ha-de-se-cuidar-da-vida-o-segredo-da-convivencia-com-osemi-arido-brasileiro/>, em 13 de março de 2019.

Revista do GELNE, Natal/RN, Vol. 21 - Número 1: p. 47-62. 2019 
mas nenhuma ocorrência do tipo ilustrado em (38d).

As expressões cristalizadas da classe PB-CPP também apresentam correspondência com os verbos das classes locativas $35 \mathrm{LD}$ e $37 \mathrm{LD}$, respectivamente, verbos com um e com dois complementos locativos. Recorde-se, porém, que a classe de ECs PB-CPP se define por apresentar dois complementos preposicionados fixos com o verbo. Um exemplo claro deste tipo de construções cristalizadas é dado em (39a):

(39) a. O Pedro foi da água para o vinho.

(39) b. O Pedro foi de Lisboa para Paris.

Contudo, a maioria destas ECs reunidas em PB-CPP apresentam apenas um complemento, cuja cabeça é fixa com o verbo. Este nome, cabeça do constituinte, é acompanhado de um complemento determinativo, geralmente introduzido por de, que também é fixo. Veja-se, por exemplo, (40a) e (41a):

(40) a. O Pedro mergulhou na boca do lobo.

(40) b. O Pedro mergulhou na piscina.

(PB-CPP)

(41) a. O Pedro chegou a um ponto sem retorno.

(41) b. O Pedro chegou a casa.

$\mathrm{Na}$ frase (40a), a expressão cristalizada apresenta um único complemento com dois elementos fixos: a cabeça do constituinte (a boca) e o seu complemento determinativo (do lobo). A relação metonímica (parte-todo) entre boca e lobo deixam clara a análise do complemento verbal como um único constituinte. Já em (41a), apesar da presença da preposição sem, trata-se também de um único complemento do verbo. Em ambos os exemplos, o complemento determinativo não pode ser destacado do nome que modifica, por exemplo, através da extração ser ... que:

Foi na boca do lobo que o Pedro mergulhou.

*Foi na boca que o Pedro mergulhou do lobo.

*Foi do lobo que o Pedro mergulhou na boca.

Foi a um ponto sem retorno que o Pedro chegou.

*Foi a um ponto que o Pedro chegou sem retorno.

*Foi sem retorno que o Pedro chegou a um ponto.

Apesar disso, é possível considerar, numa leitura sequencial/linear, como fez Vale (2001), que estas ECs, ilustradas em (40a) e (41a), apresentam dois complementos preposicionais, sem levar em conta as relações de dependência entre eles, o que levará assim a integrá-las em PB-CPP, a par de expressões como (39a). Tal permite, assim, compreender que as ECs sejam postas em relação quer com verbos da classe 35LD (com um complemento locativo) como da classe 37LD (com dois complementos locativos).

Das 60 EC da classe PB-CPP, 36 relacionam-se à classe 35LD e 18 são formadas com verbos locativos da classe 37LD.

Terminamos esta seção com algumas observações gerais sobre os complementos locativos nas construções cristalizadas aqui analisadas. A interpretação de nomes como lugar não é um processo simples, inclusive nas construções livres. Tal interpretação depende, principalmente, da posição sintática que o nome ocupa em relação ao verbo (ou a outro elemento predicativo da frase) de que depende. O nome comum ônibus, por exemplo, ocupa a posição de sujeito em (42a) e a posição de complemento locativo em (42b): 
(42) a. O ônibus chegou à parada.

(42) b. O Pedro entrou no ônibus.

Em (42a), ônibus é interpretado como o objeto do lugar (e parada é o lugar). Ao passo que em (42b), ônibus é o lugar (de destino) de Pedro (objeto do lugar).

Em muitas expressões cristalizadas construídas com verbos locativos, a interpretação de lugar torna-se mais opaca devido à combinação, por vezes surpreendente, do verbo com os nomes que ocupam a posição de complemento. Verifica-se esta opacidade na frase (39a), ir da água para o vinho, em que os nomes água e vinho são fixos com o verbo, ocupando os lugares estruturais que, na construção livre do verbo ir (37LD), correspondem às posições de locativo de origem e de destino. Deste modo, a expressão apresenta os seguintes aspectos: (i) mantém a estrutura sintática da construção livre do verbo ir, (ii) mantém (pelo menos parcial ou metaforicamente) o significado de verbo locativo de movimento, nomeadamente de deslocamento de um ponto de origem/partida a um ponto de destino/chegada; mas (iii) distancia-se da construção livre ao apresentar nomes nas posições de complementos que não são comumente interpretados como lugar, e que no seu significado literal não ocorrem facilmente nessa combinação com o verbo ir.

Há também classes específicas de nomes próprios que são particularmente aptas a designar um lugar. Os chamados topônimos são dos nomes próprios aqueles que geralmente se enquadram melhor na posição sintática de complemento de lugar e que, segundo Ramos (2008), têm como função primeira referenciar e identificar um lugar, como em (43), com Espanha:

O Pedro percorreu toda a Espanha à procura desse livro.

Este tipo de nome entra também na formação de algumas ECs, mas perdem, nessa situação, o seu valor denotativo. Encontramos, neste trabalho, apenas uma expressão que seleciona um topônimo na posição de complemento e cujo sentido só pode ser determinado com base no contexto, como se verifica no exemplo (44a).

$$
\begin{aligned}
& \text { a. O Pedro foi para o Acre. } \\
& \text { b. O Pedro foi para (a cidade dos pés juntos }+ \text { para um bom lugar }+ \\
& \text { para o outro mundo). }
\end{aligned}
$$

Em outros casos, (44b), encontramos vários vocábulos associados ao conceito de lugar, tais como, cidade, lugar e mundo, o que reafirma a relação da EC com a construção livre, que, por algum processo sócio-histórico-cultural, parece haver possibilitado a formação da expressão cristalizada. Efetivamente, nas construções livres, segundo Borba et al. (1990, p. XVIII), o lugar ou locativo pode englobar tanto uma localização física, como em (45a), quanto uma localização não-física (45b), como sucede nas expressões cristalizadas, ainda que estas tenham um caráter idiomático.

a. O Pedro foi para o supermercado.

b. O Pedro foi (para o inferno + para o céu + para o paraíso).

Em síntese, a partir dos exemplos apresentados foi possível identificar uma clara correspondência entre as construções livres e as expressões cristalizadas construídas com verbos locativos. Tais expressões tendem a manter uma estrutura sintática idêntica à das construções livres dos verbos que entram na sua formação ou a apresentar uma estrutura sintática parcialmente idêntica à das construções livres correspondentes, podendo o número de complementos da EC ser diferente do da construção verbal livre. Por outro lado, algumas 
expressões apresentam nomes claramente associados ao conceito de lugar, enquanto outras exibem combinações surpreendentes com nomes dificilmente interpretáveis como lugar.

\section{CONSIDERAÇÕES FINAIS}

Neste artigo, (i) realizamos a descrição da proposta de classificação sintático-semântica dos verbos locativos do português, representados na base de dados ViPEr (BAPTISTA, 2013); (ii) fizemos a descrição da proposta de classificação sintática das expressões cristalizadas do português do Brasil (VALE, 2001); e (iii) procedemos à análise das relações que se estabelecem entre as construções das expressões cristalizadas e as construções livres dos verbos que entram na formação daquelas expressões.

Das 3.551 expressões cristalizadas descritas por Vale (2001), 827 expressões envolvem verbos locativos, segundo a classificação do ViPEr (BAPTISTA, 2013), o que revela a dimensão do fenômeno das construções locativas, enquanto base para a formação de expressões cristalizadas em língua portuguesa. Dessas 827 expressões cristalizadas "locativas", mais de $50 \%$ (425/827) se relaciona a verbos da classe 38LD do ViPEr, os quais selecionam um complemento direto com valor de objeto e um complemento preposicionado locativo de destino (pregar chiclete na cruz $^{\mathrm{EC}}$ vs. pregar um quadro na parede $\left.{ }^{\mathrm{CL}}\right)$.

A partir da análise caso a caso, foram traçadas três principais correspondências no alinhamento expressões cristalizadas - construções verbais livres, a saber: (i) a expressão cristalizada apresenta uma estrutura sintática idêntica à da construção livre (subir o morro ${ }^{\mathrm{EC} / \mathrm{CL}}$, suar a camisa $\left.^{\mathrm{EC} / \mathrm{CL}}\right)$, podendo até dar origem a expressões formalmente ambíguas com construções livres, situação em que o sentido preciso da expressão só pode ser determinado a partir do contexto (ou da situação comunicativa) em que é empregue; (ii) a expressão cristalizada apresenta uma estrutura sintática idêntica à da construção livre, mas o verbo forma combinações surpreendentes com nomes geralmente não interpretáveis como lugar (ir da água para o vinho ${ }^{\mathrm{EC}}$ vs. ir de Lisboa para Paris ${ }^{\mathrm{CL}}$ ); e (iii) a expressão cristalizada apresenta variação na estrutura sintática, com um diferente número de complementos daquele que se observa na construção livre do verbo correspondente (carregar o piano ${ }^{\mathrm{EC}}$ vs. carregar o piano para o caminhãa ${ }^{\mathrm{CL}}$ ).

Apesar de se poder afirmar que todas estas ECs são idiomáticas, no sentido em que o seu significado global não é composicional, e considerando-se um maior ou menor grau de opacidade das expressões cristalizadas, é possível afirmar que muitas expressões aqui estudadas conservam parte substancial do significado e da construção verbal que serviu de base à sua formação.

\section{AGRADECIMENTOS}

Os autores agradecem aos apoios financeiros da FAPESP - Fundação de Amparo à Pesquisa do Estado de São Paulo, Brasil (Processos: 2016/20545-0 e 2016/24670-3) e da FCT - Fundação para a Ciência e a Tecnologia, Portugal (UID/CEC/50021/2019).

\section{REFERÊNCIAS BIBLIOGRÁFICAS}

BAPTISTA, J.; CORREIA, A.; FERNANDES, G. Léxico-gramática das frases fixas do portugués europeo: Breve presentación. Cadernos de Fraseoloxía Galega 7, Santiago de Compostela, p. 41-53, 2005.

BAPTISTA, J. ViPEr: uma base de dados de construções léxico-sintáticas de verbos do Português Europeu. Textos Selecionados. XXVIII Encontro Nacional da Associação Portuguesa de Linguística. Coimbra: APL, p. 111-129, 2013.

BORBA, F. S. Dicionário gramatical de verbos do português contemporâneo do Brasil. São Paulo: Editora da Universidade Estadual Paulista, 1990. 
CANÇADO, M., GODOY, L.; AMARAL, L. Catálogo de verbos do português brasileiro: classificação segundo a decomposição de predicados: verbos de mudança. Belo Horizonte: Editora UFMG, 2013.

CORRÊA, R.; CANÇADO, M. Verbos de Trajetória do PB: uma descrição sintático-semântica. Revista de Estudos da Linguagem. Belo Horizonte, 2006. p. 371-404.

GUILLET, A.; LECLÈRE, C. La structure des phrases simples en français: constructions transitives locatives. Genebra: Librairie Droz S.A, 1992.

GROSS, M. Méthodes en syntaxe. Paris: Hermann, 1975.

GROSS, M. Les bases empiriques de la notion de prédicat sémantique. Langages, n. 63, p. 7-52, 1981.

GROSS, M. Une classification des phrases figées du français. Revue québécoise de linguistique, 11(2), p. 151-185, 1982.

MACEDO, M. E. Construçẽes Transitivas Locativas. Centro de Linguística da Universidade de Lisboa, Lisboa, 1987.

NEVES, M. H. M. Gramática de usos do português. São Paulo: Editora da Universidade Estadual Paulista, 2000.

RAMOS, R. T. Em busca de uma caracterização geral do topônimo. In: Cadernos do CNLF. Volume XII, Caderno 9. Rio de Janeiro: Instituto de Letras da UERJ, 2008.

RODRIGUES, R. Análise contrastiva dos verbos locativos do português do Brasil e do português europeu. Dissertação (Mestrado) em Linguística. Universidade Federal de São Carlos (UFSCar), São Carlos, 2016.

VALE, O. A. Expressões Cristalizadas do Português do Brasil: uma proposta de tipologia. Tese (Doutorado) em Linguística. Faculdade de Ciências, Letras e Artes, Universidade Estadual Paulista (UNESP), Araraquara, 2001.

Submetido em 27/11/2018

Aceito em 08/02/2019

Publicado em 21/03/2019 